\title{
Profile of belinostat for the treatment of relapsed or refractory peripheral T-cell lymphoma
}

This article was published in the following Dove Press journal:

OncoTargets and Therapy

24 October 2014

Number of times this article has been viewed

\author{
Andrew Bodiford' \\ Megan Bodge' \\ Mahsa S Talbott \\ Nishitha M Reddy ${ }^{2}$ \\ 'Department of Pharmacy, \\ ${ }^{2}$ Division of Hematology and \\ Oncology, Department of Medicine, \\ Vanderbilt University Medical Center, \\ Nashville, TN, USA
}

\begin{abstract}
The peripheral T-cell lymphomas are a rare and heterogeneous group of mature T-cell lymphomas with limited available therapies. The outcome of frontline chemotherapy regimens has been disappointing, with a long-term survival of only $20 \%-30 \%$. There is an urgent need to optimize induction therapy by incorporating novel agents that target the dysregulated pathways. Histone deacetylase inhibitors that induce acetylation of histones and enhance apoptosis have shown promising activity. In this article, we summarize the role of histone deacetylase inhibitors and specifically discuss pharmacokinetics, efficacy, and toxicity of the recently US Food and Drug Administration-approved agent belinostat for its use in patients with relapsed/refractory peripheral T-cell lymphoma.
\end{abstract}

Keywords: histone deacetylase inhibitor, pharmacokinetics, cutaneous T-cell lymphoma

\section{Introduction}

The incidence of peripheral T-cell lymphoma (PTCL) is less than one case per 100,000 people in the United States, which represents $10 \%-20 \%$ of all cases of nonHodgkin lymphoma. Although this heterogeneous subtype of non-Hodgkin lymphoma is rare, PTCL has a poor prognosis with a median overall survival (OS) of 9-42 months, and there are limited effective therapeutic options. ${ }^{1}$ There are over 22 subtypes of PTCL that have been identified. The major subtypes are PTCL, not otherwise specified (PTCL-NOS), anaplastic large cell lymphoma (ALCL), and angioimmunoblastic T-cell lymphoma (AITL), with differences in regional occurrence. ${ }^{2}$ The aggressive subtype, natural killer/T-cell lymphoma, is more common in Asia and rarely seen in European and North American countries. ${ }^{2}$ PTCL-NOS has been reported as the major subtype worldwide and typically represents a variant that does not meet criteria for other subtypes. Both PTCL-NOS and AITL typically affect elderly patients and portend a poor prognosis with an expected $20 \%-30 \% 5$-year OS. ALCL is associated with anaplastic lymphoma kinase (ALK) amplification, which occurs in approximately $50 \%$ of all ALCL cases. ${ }^{3}$

There has been little success in determining the most appropriate and efficacious treatment regimen for PTCL as evidenced by the low reported median OS. Initial treatment intent is typically curative while treatment of relapsed/refractory disease is often palliative in nature. A 2007 retrospective meta-analysis evaluated anthracycline-based regimens in 2,912 patients with PTCL, and it was determined that patients who received this type of regimen experienced a 5 -year OS of $37 \%$. Current treatment recommendations include anthracycline-based regimens such as cyclophosphamide, doxorubicin, vincristine, and prednisone (CHOP). ${ }^{4}$ Other more intensive treatment options that have 
been investigated include doxorubicin, cyclophosphamide, vindesine, bleomycin, and prednisone (ACVBP); variations of CHOP such as CHOP-14 and CHOP-21; and etoposide, vincristine, doxorubicin, cyclophosphamide, and prednisone (EPOCH), with similar results observed with CHOP. ${ }^{2}$ Many of these treatment modalities are based upon research with B-cell lymphomas due to the success seen in this type of lymphoma. In the end, these regimens are still expected to only have a median 5 -year OS of less than $40 \%{ }^{2}$ Therefore, there is a need for further research to validate more efficacious treatment regimens. Prior clinical trials evaluating the most appropriate first-line treatment for PTCL have included a variety of chemotherapy regimens and hematopoietic stem cell transplantation. For these reasons, there is currently a heterogeneous approach to initial treatment.

Currently, the available evidence provides no clear indication towards a preferred regimen. ${ }^{5}$ Autologous stem cell transplantation is an option for patients with PTCL with 3-5-year event-free survival ranging from 30\%-50\%; however, there is controversy regarding the timing of when to implement this treatment strategy. ${ }^{6}$ Previous evaluations have determined that autologous stem cell transplantation is only effective for the patient population with chemosensitive disease. This was found to be one of the strongest predictor values in terms of outcome. ${ }^{7}$ Transplantation is an option for the first relapse in patients with ALCL or another option for patients with PTCL-NOS or AITL who are not enrolled in a clinical trial and experience a complete response. A recent prospective Phase II trial evaluated a combination chemotherapy regimen with consolidation therapy followed by stem cell transplantation versus traditional chemotherapy (six courses of CHOP-21 plus alemtuzumab). Patients were randomized to either CHOP-21 + alemtuzumab for two cycles, followed by HyperCHidam (high-dose methotrexate, cyclophosphamide, and high-dose cytarabine) for two cycles, and in the end, patients either underwent transplant or received CHOP-21 + alemtuzumab for six cycles. Patients who were 60 years-old or younger were stratified to the transplant arm while patients older than 60 and younger than 75 years-old were stratified to the traditional chemotherapy arm. After a median follow-up of 40 months, the 4-year OS was 49\% for the transplant arm versus $31 \%$ in the traditional chemotherapy arm. The authors concluded that first-line allogeneic or autologous stem cell transplantation is effective in the younger population in terms of clinical outcomes. ${ }^{8}$ Small sample populations and including multiple subtypes of PTCL limit the ability to draw definitive conclusions when determining the efficacy of stem cell transplantation.
Resistance to chemotherapy treatment for PTCL can occur through the overexpression of P-glycoprotein, a multidrug resistance protein that is often expressed in T-cell lymphoma, specifically in natural killer/T lymphoma. ${ }^{9}$ This can increase lymphoma cells' resistance to medications, further compounding chemotherapy's futile application in the treatment of PTCL. ${ }^{10}$ Extensive research has been conducted to evaluate treatment options for relapsed/refractory disease. Novel therapeutic options that have been evaluated include gemcitabine, pralatrexate, allogeneic stem cell transplantation, monoclonal antibodies, and the histone deacetylase (HDAC) inhibitors (HDACi). ${ }^{11}$ In this review, we discuss the role of HDACi in T-cell lymphoma.

\section{HDAC expression in lymphoma}

HDACs are overexpressed in several tumor types and may play a pivotal role in tumor growth via transcriptional repression of tumor suppressor genes. The expression of HDAC1, HDAC2, HDAC6, and acetylated H4 was evaluated using immunohistochemical staining in 76 patients with lymphoma (31 diffuse large B-cell lymphoma and 45 PTCL). HDAC1 was expressed significantly higher in PTCL than in DLBCL, suggesting a probable mechanism of tumor suppression and sensitivity to HDACi in T-cell lymphoma. ${ }^{12}$ In a study of 73 patients with cutaneous T-cell lymphoma (CTCL), it was noted that HDAC1 and HDAC2 were abundantly expressed, followed by HDAC6 and $\mathrm{H} 4$ acetylation. ${ }^{13}$

\section{HDACi in T-cell lymphoma}

HDACi play a crucial role in the acetylation and deacetylation of histones and exert their action through removing acetyl groups from histones. The deacetylation of histones results in a more condensed chromatin structure, which causes transcriptional deactivation. Transcriptional deactivation allows undifferentiated growth and cell proliferation (Figure 1). Chromatin is found in the nucleus of many eukaryotic cells and is composed of DNA and proteins. A major function of chromatin is to protect DNA from damage. Histones are a major protein that comprise chromatin, and there has been increased interest over the past decade in the aberrant process of histone modifications, specifically histone acetylation. Levels of acetylation are balanced by histone acetyl-transferase and HDAC, and this balance plays a role in gene transcription/regulation as well as DNA repair. HDAC exerts its activity by removing acetyl groups from lysine located on histones, causing a more compact chromatin. This formation causes transcriptional gene silencing, resulting in increased potential for 


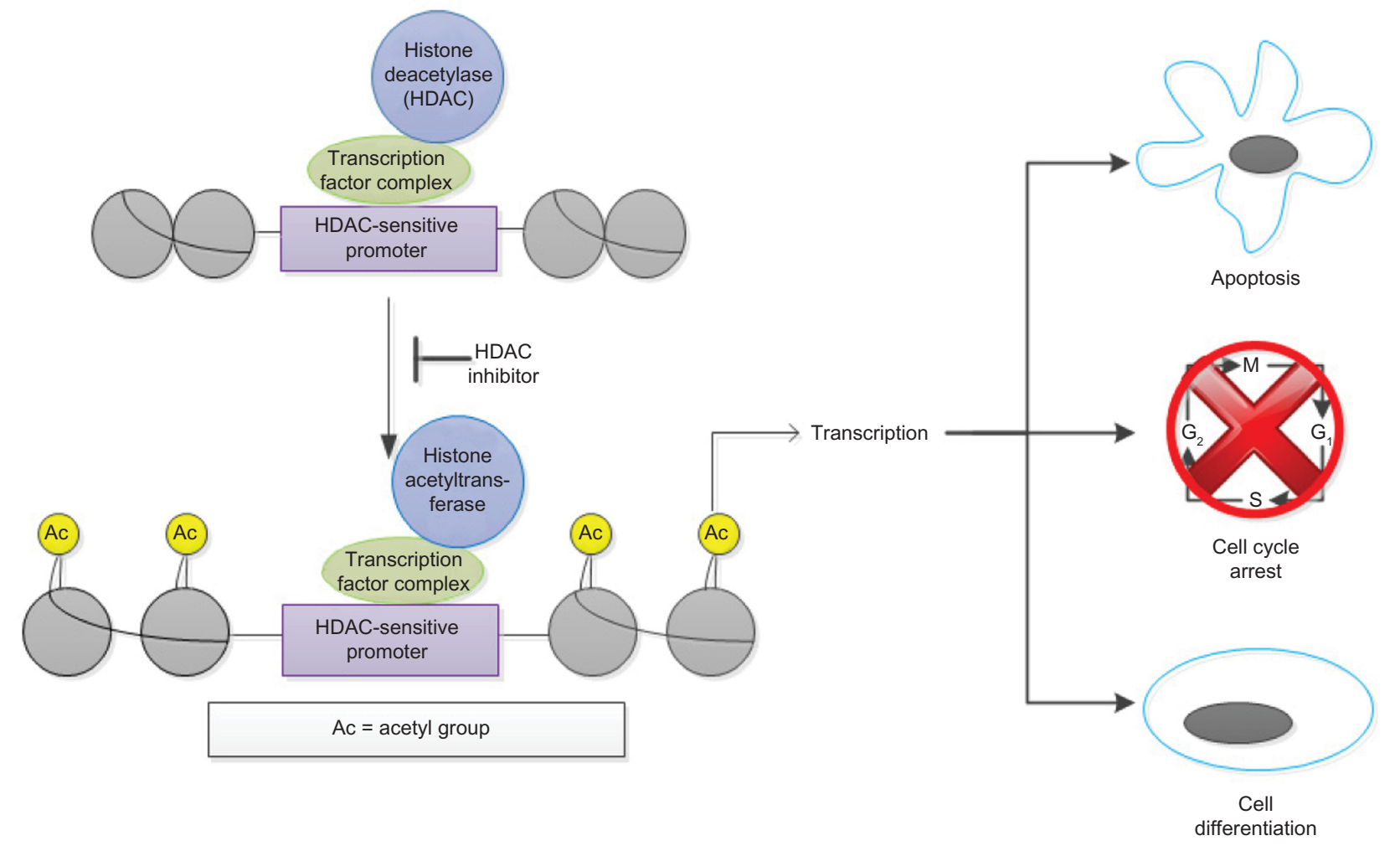

Figure I Pharmacology of histone deacetylase (HDAC) inhibitors.

Note: Belinostat allows hyperacetylation of suppressed genes, resulting in cell growth and/or apoptosis in malignant cells.

unregulated cell proliferation. There are approximately 18 different HDACs categorized into four classes, where HDACi inhibit class I and II. Class I HDACs regulate cell proliferation, while class II suppress apoptosis in malignant cells. ${ }^{14}$ Through this inhibition, HDACi exert its antineoplastic activity by allowing hyperacetylation of suppressed genes, resulting in cell growth arrest and/or apoptosis in malignant cells. ${ }^{15} \mathrm{~A}$ more comprehensive explanation of this mechanism of action has been described previously. ${ }^{16}$

There are three drugs that have received approval by the US Food and Drug Administration (FDA) in lymphoma (Table 1).

A previous Phase II clinical trial evaluated patients with refractory PTCL who were treated with romidepsin. There were 47 patients included in this investigation who had a median of three prior treatments. The overall response rate (ORR) was $38 \%$, and eight patients had a complete response to therapy. The median duration of response was 8.9 months with a range from 2-74 months. ${ }^{17}$

Vorinostat is an organic hydroxamic acid that inhibits both class I and II HDAC proteins. In a single arm, Phase II, multicenter trial in patients with relapsed/refractory CTCL, vorinostat demonstrated an ORR of $29.7 \%$, with duration of response that lasted 6 months. ${ }^{18}$ Panobinostat, another oral
HDACi, has been evaluated in patients with CTCL, with a response rate of $12.5 \%{ }^{19}$

Belinostat is a novel HDACi that is currently being evaluated in Phase II trials in patients with relapsed or refractory PTCL. It has also been evaluated in a number of other malignancies including ovarian and other solid tumor cancers. ${ }^{20}$ The FDA recently granted approval for this medication, which was determined based upon results from the single arm, Phase II, BELIEF study. This medication is available for intravenous administration only. ${ }^{21}$ To date, there are three FDA-approved HDACi for T-cell lymphoma (two for relapsed CTCL and one for relapsed PTCL)

\section{Preclinical and Phase I studies}

The pharmacokinetic profile of belinostat has previously been investigated in dogs and rats. Two-compartment kinetics with rapid distribution was found with both intravenous and oral administration. The elimination half-life was 1-2 hours, and bioavailability was noted to be roughly $30 \%$ in dogs. Metabolism was rapid, and metabolites were mainly excreted through bile and/or feces. ${ }^{29}$

A Phase I pharmacokinetic and pharmacodynamic trial was conducted in humans with advanced solid tumors. Elimination half-life ranged from $0.3-1.3$ hours, and dose had 
Table I Histone deacetylase inhibitors in lymphoma

\begin{tabular}{|c|c|c|c|c|c|}
\hline Medication & $\begin{array}{l}\text { Route } \\
\text { of administration }\end{array}$ & $\begin{array}{l}\text { HDAC classes } \\
\text { inhibited }^{22}\end{array}$ & Indications & Response rates & Side effects \\
\hline $\begin{array}{l}\text { Romidepsin } \\
\text { (FDA approved) }\end{array}$ & Intravenous & $\begin{array}{l}\text { Class I } \\
\text { (slight inhibition } \\
\text { of class II) }\end{array}$ & $\begin{array}{l}\text { Cutaneous T-cell } \\
\text { lymphoma } \\
\text { Peripheral T-cell } \\
\text { lymphoma }\end{array}$ & $\begin{array}{l}\text { ORR: } 34 \%-35 \% 23 \\
\text { ORR: } 25 \%-38 \%{ }^{17,24}\end{array}$ & $\begin{array}{l}\text { Nausea, increased risk } \\
\text { for infection, fatigue, } \\
\text { thrombocytopenia, QTc } \\
\text { prolongation (rare) }{ }^{17}\end{array}$ \\
\hline $\begin{array}{l}\text { Vorinostat } \\
\text { (FDA approved) }\end{array}$ & Oral & Class I and II & $\begin{array}{l}\text { Cutaneous T-cell } \\
\text { lymphoma } \\
\text { Follicular lymphoma }\end{array}$ & $\begin{array}{l}\text { ORR: } 24.2 \%-36 \%^{18,25} \\
\text { ORR: } 35 \%^{23}\end{array}$ & $\begin{array}{l}\text { Diarrhea, fatigue, nausea, } \\
\text { anorexia, thrombocytopenia, } \\
\text { and anemia }{ }^{18,25}\end{array}$ \\
\hline $\begin{array}{l}\text { Panobinostat } \\
\text { (under evaluation) }\end{array}$ & Oral & Class I, II, and IV & $\begin{array}{l}\text { Cutaneous T-cell } \\
\text { lymphoma } \\
\text { Hodgkin lymphoma }\end{array}$ & $\begin{array}{l}\text { ORR: } 20 \%{ }^{23} \\
\text { ORR: } 22 \%-24 \%{ }^{23}\end{array}$ & $\begin{array}{l}\text { Anorexia, nausea, fatigue, } \\
\text { diarrhea, thrombocytopenia, } \\
\text { and anemia }{ }^{26}\end{array}$ \\
\hline $\begin{array}{l}\text { Belinostat } \\
\text { (FDA approved) }\end{array}$ & Intravenous & Pan-inhibitor & $\begin{array}{l}\text { Cutaneous T-cell } \\
\text { lymphoma } \\
\text { Peripheral T-cell } \\
\text { lymphoma }\end{array}$ & $\begin{array}{l}\text { ORR: } 14 \%^{27} \\
\text { ORR: } 26 \%{ }^{28}\end{array}$ & $\begin{array}{l}\text { Nausea, vomiting, lethargy, } \\
\text { fatigue, constipation, } \\
\text { flushing, and diarrhea }{ }^{27,28}\end{array}$ \\
\hline
\end{tabular}

Abbreviations: FDA, US Food and Drug Administration; HDAC, histone deacetylase; ORR, overall response rate; QTc, corrected QT interval.

no effect on this pharmacokinetic parameter. Low amounts $(0.2 \%-2 \%$ of total administered dose $)$ of parent drug were seen after elimination.

The pharmacokinetics of belinostat was also evaluated in 17 patients with hepatocellular carcinoma. Doses ranged from $600-1,400 \mathrm{mg} / \mathrm{m}^{2}$. The primary objective was to determine the major metabolic pathway for belinostat, and the authors hypothesized that glucuronidation would prove to be the main pathway since this was observed with other HDACi. Five metabolites were found, and the primary metabolite was belinostat-G. The authors confirmed that glucuronidation is the primary metabolic pathway. Two other minor pathways were found: methylation and reduction of a hydroxamic group on belinostat.

The maximum tolerated dose (MTD) was determined in a Phase I study in patients with solid tumors. The dose range was $150-1,200 \mathrm{mg} / \mathrm{m}^{2} /$ day, and this was given intravenously over 30 minutes in 46 patients. Patients received this agent on days $1-5$ on a 21 -day cycle. Dose-limiting toxicities included fatigue, nausea, vomiting, diarrhea, and atrial fibrillation, and the MTD was set as $1,000 \mathrm{mg} / \mathrm{m}^{2} /$ day. ${ }^{14}$ The impact of targeting $\mathrm{H} 4$ acetylation was specifically evaluated in patients with advanced solid tumors. Hyperacetylation of $\mathrm{H} 4$ was seen after each infusion, and this effect persisted for 4-24 hours. The dose did have an effect on how long hyperacetylation lasted, where increased acetylation returned to baseline levels 2 hours after infusion was complete. When higher doses were administered, this effect could last as long as 24 hours after infusion. This dose-related effect seemed to plateau at $900 \mathrm{mg} / \mathrm{m}^{2} .^{30}$ A parallel Phase I study in patients with advanced hematological malignancies determined a recommended dose of $1,000 \mathrm{mg} / \mathrm{m}^{2} /$ day, days $1-5$ in a 21 day cycle for Phase II studies. ${ }^{31}$
The feasibility of oral administration, and most importantly the pharmacokinetic profile of oral belinostat, was evaluated in a range of varying doses and schedules. A dose of $1,000 \mathrm{mg} / \mathrm{m}^{2}$ twice daily for 5 consecutive days was well tolerated and prolonged the drug exposure to the intended target. ${ }^{32}$ In patients with advanced solid tumors, a continuous dosing of $250 \mathrm{mg}$ daily or twice daily was tolerated. ${ }^{33}$ In another dosing schedule in patients with advanced lymphoma, an oral dose of $1,250 \mathrm{mg}$ daily on days $1-14$ every 3 weeks was safe and also effective as noted by tumor shrinkage in patients with mantle cell and Hodgkin lymphoma. ${ }^{34}$ The optimal dose and schedule of oral administration, however, has not been established.

The majority of pharmacodynamics analyses have been conducted to describe the effect of belinostat on the acetylation of histones 3 and 4 (H3 and H4). Plumb et al ${ }^{35}$ assessed the acetylation activity of both of these histones after belinostat exposure. An obvious increase in the level of acetylation was seen both in vivo and in vitro. Growth inhibition and apoptosis of the malignant cells were associated with these increased levels of acetylation, and no noticeable toxicity was seen in mice.

\section{Clinical efficacy}

In 2009, Pohlman et $\mathrm{al}^{27}$ evaluated efficacy and safety of belinostat in patients with either CTCL or PTCL. There were 20 patients with PTCL included in this analysis. A $25 \%$ response rate was observed with two complete responses and three partial responses in patients with PTCL. The median duration of response was 159 days; a few were durable responses that lasted greater than 504 days by the end of the observation period. Stable disease was seen in five patients. 
Belinostat demonstrated clinical benefit for patients with refractory or relapsed PTCL in a recent Phase II clinical trial, the BELIEF trial. ${ }^{36}$ The evidence available for its use in PTCL is mostly limited to this analysis. This was a singlearm study in which patients with PTCL who had failed at least one prior treatment were eligible for enrollment. The primary study objective was to assess the safety and efficacy of single-agent belinostat in refractory or relapsed PTCL. Inclusion criteria included platelet counts of $50,000 / \mu \mathrm{L}$ or greater, no prior HDACi therapy, and no relapse within 100 days of autologous or allogeneic bone marrow transplant. The primary endpoint was the ORR and secondary endpoints were safety, time to response, progression-free survival, duration of response, and OS. Response by PTCL subtype was also evaluated. Belinostat $1,000 \mathrm{mg} / \mathrm{m}^{2}$ was administered as a 30-minute intravenous infusion on days $1-5$ of a 21 -day cycle until disease progression or unacceptable toxicity. There were 129 patients with relapsed or refractory PTCL who received belinostat for a median of two cycles (range $1-33)$. The population was predominantly male (53\%), and the median age was 63 years-old. The majority of patients received $\mathrm{CHOP} / \mathrm{CHOP}-$ like regimens prior to enrollment (96\%), and the median number of systemic therapies was two. A smaller proportion (23\%) of patients had previously undergone stem-cell transplantation prior to enrollment. After confirmation of PTCL by central pathology review, there were 120 patients who were eligible for evaluation. Seven patients died prior to first radiologic assessment, ten had clinical progression, five withdrew from the trial, and one was lost to follow up. Twenty-six percent of the remaining patients demonstrated an ORR with $11 \%$ having a complete response and $15 \%$ a partial response. Stable disease was seen in $15 \%$ while $40 \%$ had progressive disease. In terms of the three most common subtypes, ORR was seen in $23 \%$ of patients with PTCL-NOS ( $\mathrm{n}=77), 46 \%$ in AITL ( $\mathrm{n}=22)$, and $15 \%$ in ALCL, ALK-negative $(n=13)(0 \%$ in ALK-positive $[n=2])$. Secondary outcomes are detailed in Table 2. The authors concluded that belinostat can be a novel therapeutic option for patients with low bone marrow reserve and/or thrombocytopenia. Belinostat also demonstrated a possible therapeutic advantage in patients with AITL with a greater

Table 2 Clinical outcomes of patients treated with belinostat

\begin{tabular}{ll}
\hline Secondary outcomes & All patients $(\mathbf{n}=\mathbf{I} \mathbf{2 0})$ \\
\hline Median time to response & 5.6 weeks $(5.6-6.4$ weeks $)$ \\
Median progression-free survival & 1.6 months (I.3-I.8 months) \\
Median overall survival & 7.9 months (4.3-9.2 months) \\
Median duration of response & 13.6 months (4.I-I3.6 months) \\
\hline
\end{tabular}

ORR and a median progression-free survival of 4.2 months versus 1.6 months seen in all subtypes. ${ }^{27}$

\section{Safety}

The safety profile of belinostat has been previously investigated in a Phase I clinical trial. Groups of three to six patients with advanced solid tumors were enrolled sequentially into escalating dose steps. The dose was increased in $100 \%$ increments until grade 2 toxicities were noted. After this, a sequential dose increase occurred such that the dose was increased by $50 \%$ until grade 3 toxicities were observed, and then 33\% thereafter. National Cancer Institute's Common Terminology Criteria for Adverse Events, version 3.0 was utilized to grade toxicities. The most common adverse events (occurred in $\geq 15 \%$ of patients) were nausea, vomiting, lethargy, fatigue, constipation, flushing, and diarrhea. There were no hematological or grade 4 adverse reactions observed at any dosing regimen. The MTD was found to be $1,000 \mathrm{mg} / \mathrm{m}^{2} \cdot{ }^{30,31}$

Safety analysis conducted by Pohlman et $\mathrm{al}^{27}$ showed a small subset of the patient population experienced hematological toxicities. One had grade 3 neutropenia, one had grade 3 thrombocytopenia, and none had grade 4 hematological adverse reaction. There were only four grade 3/4 adverse events reported, which included pruritus, rash/erythema, edema, and paralytic ileus. The authors concluded that belinostat was generally well tolerated in patients with either CTCL or PTCL.

The largest safety analysis of belinostat to date was conducted in the BELIEF trial. There were 120 patients available for analysis who had PTCL confirmed by central pathology review. The most common grade $3 / 4$ adverse events included thrombocytopenia and neutropenia, which occurred in $13 \%$ of patients, respectively. Other common grade $3 / 4$ adverse events were anemia (10\%), dyspnea (6\%), pneumonia (6\%), and fatigue $(5 \%)$. The authors concluded that belinostat was well tolerated in patients with platelet counts below $100,000 / \mu \mathrm{L}$, demonstrating a possible therapeutic benefit for this medication. Progressive disease in $64 \%$ of patients was the major cause for drug discontinuation. Other causes included death (11\%), request by patient ( $8 \%$ ), adverse events $(7 \%)$, and other $(4 \%){ }^{28}$

\section{Current implications}

Belinostat has been included in the National Comprehensive Cancer Network guidelines as second line therapy for patients with relapsed PTCL and may be considered to obtain a remission prior to stem cell transplantation. ${ }^{36}$ 
There are several Phase II single agent studies evaluating the role of a variety of agents in different classes such as immunomodulators, other HDACi, nucleoside analogs, monoclonal antibodies, or fusion proteins in relapsed PTCL. Current data does not support a specific recommendation in sequencing these agents after failure of frontline therapy. The toxicity profile of the individual drugs may guide the preferential use of one agent over the other. Another consideration is the dosing schedule of these agents that may depend on patient convenience. The treating physician should also consider the subtype of lymphoma while recommending treatment. Not all subtypes of T-lymphoma have been included in the various studies. Most of the studies were conducted in small Phase II studies and do not include all subtypes of lymphoma. Subgroup analysis of these small studies may not be a fair comparison; however, they may hint toward initial selection of therapy.

\section{Future directions}

Relapsed PTCL has historically carried a very poor prognosis, with few therapeutic options. To date, belinostat monotherapy has been evaluated in relapsed/refractory PTCL with promising results. Future evaluations should be directed at determining the efficacy of combination regimens that include belinostat. Enrollment is currently ongoing in a clinical trial that evaluates the use of belinostat in combination with CHOP (BelCHOP) for treatment of PTCL (NCT01839097). Other combinations include belinostat with paclitaxel and carboplatin and belinostat with bortezomib (NCT01310244; NCT01075425). Outside of PTCL, oral belinostat is being evaluated for its use in solid tumor malignancies, and this could represent more opportunities for this medication. Belinostat's efficacy is being evaluated for use in refractory acute leukemia, myelodysplastic syndrome, and nonsmall-cell lung cancer. As a single agent, this novel pan-HDACi could possibly represent a breakthrough in the treatment of PTCL among other malignancies. Given its modest efficacy as a single agent, combination therapies with other chemotherapeutic or targeted agents that demonstrate efficacy and tolerability would be considered an attractive strategy in patients with PTCL.

\section{Disclosure}

The authors report no conflicts of interest in this work.

\section{References}

1. Reimer P, Chawla S. Long-term complete remission with belinostat in a patient with chemotherapy refractory peripheral T-cell lymphoma. J Hematol Oncol. 2013;6:69.
2. Foss FM, Zinzani PL, Vose JM, Gascoyne RD, Rosen ST, Tobinai K. Peripheral T-cell lymphoma. Blood. 2011;117(25):6756-6767.

3. Hamadani M, Abu Kar SM, Usmani SZ, Savani BN, Ayala E, Kharfan-Dabaja MA. Management of relapses after hematopoietic cell transplantation in T-cell non-Hodgkin lymphomas. Semin Hematol. 2014;51(1):73-86.

4. Reddy NM, Savani BN. Management of T-cell lymphomas: overcoming challenges and choosing the best treatment. Semin Hematol. 2014;51(1):1-4.

5. Reddy NM, Evens AM. Chemotherapeutic advancements in peripheral T-cell lymphoma. Semin Hematol. 2014;51(1):17-24.

6. Schmitz N, Wu HS, Glass B. Allogeneic transplantation in T-cell lymphomas. Semin Hematol. 2014;51(1):67-72.

7. Giulia P, Corradini P. Autologous stem cell transplantation for T-cell lymphomas. Semin Hematol. 2014;51(1):59-66.

8. Corradini P, Vitolo U, Rambaldi A, et al. Intensified chemoimmunotherapy with or without stem cell transplantation in newly diagnosed patients with peripheral T-cell lymphoma. Leukemia. 2014;28(9):1885-1891.

9. Yamaguchi M, Kita K, Miwa $\mathrm{H}$, et al. Frequent expression of P-glycoprotein/MDR1 by nasal T-cell lymphoma cells. Cancer. 1995;76(11):2351-2356.

10. Gottesman MM. Mechanisms of cancer drug resistance. Annu Rev Med. 2002;53:615-627.

11. Karlin L, Coiffier B. The changing landscape of peripheral T-cell lymphoma in the era of novel therapies. Semin Hematol. 2014;51(1):25-34.

12. Marquard L, Poulsen CB, Gjerdrum LM, et al. Histone deacetylase 1, 2, 6 and acetylated histone H4 in B- and T-cell lymphomas. Histopathology. 2009;54(6):688-698.

13. Marquard L, Gjerdrum LM, Christensen IJ, Jensen PB, Sehested M, Ralfkiaer E. Prognostic significance of the therapeutic targets histone deacetylase 1, 2, 6 and acetylated histone H4 in cutaneous T-cell lymphoma. Histopathology. 2008;53(3):267-277.

14. Molife LR, de Bono JS. Belinostat: clinical applications in solid tumors and lymphoma. Expert Opin Investig Drugs. 2011;20(12):1723-1732.

15. Ropero S, Esteller M. The role of histone deacetylases (HDACs) in human cancer. Mol Oncol. 2007;1(1):19-25.

16. Xu WS, Parmigiani RB, Marks PA. Histone deacetylase inhibitors: molecular mechanisms of action. Oncogene. 2007;26(37):5541-5552.

17. Piekarz RL, Frye R, Prince HM, et al. Phase 2 trial of romidepsin in patients with peripheral T-cell lymphoma. Blood. 2011;117(22):5827-5834.

18. Olsen EA, Kim YH, Kuzel TM, et al. Phase IIb multicenter trial of vorinostat in patients with persistent, progressive, or treatment refractory cutaneous T-cell lymphoma. J Clin Oncol. 2007;25(21):3109-3115.

19. Duvic M, Dummer R, Becker JC, et al. Panobinostat activity in both bexarotene-exposed and -naïve patients with refractory cutaneous T-cell lymphoma: results of a phase II trial. Eur J Cancer. 2013;49(2):386-394.

20. Glaser KB. HDAC inhibitors: clinical update and mechanism-based potential. Biochem Pharmacol. 2007;74(5):659-671.

21. BELEODAQ ${ }^{\mathrm{TM}}$ (belinostat) for injection [prescribing information]. Henderson, NV: Spectrum Pharmaceuticals, Inc.; 2014.

22. New M, Olzscha H, La Thangue NB. HDAC inhibitor-based therapies: can we interpret the code? Mol Oncol. 2012;6(6):637-656.

23. Lemoine M, Younes A. Histone deacetylase inhibitors in the treatment of lymphoma. Discov Med. 2010;10(54):462-470.

24. Coiffier B. Monoclonal antibodies in the treatment of indolent lymphomas. Best Pract Res Clin Haematol. 2005;18(1):69-80.

25. Duvic M, Talpur R, Ni X, et al. Phase 2 trial of oral vorinostat (suberoylanilide hydroxamic acid, SAHA) for refractory cutaneous T-cell lymphoma (CTCL). Blood. 2007;109(1):31-39.

26. Ellis L, Pan Y, Smyth GK, et al. Histone deacetylase inhibitor panobinostat induces clinical responses with associated alterations in gene expression profiles in cutaneous T-cell lymphoma. Clin Cancer Res. 2008;14(14):4500-4510. 
27. Pohlman B, Advani R, Duvic M, et al. Final results of a Phase II trial of belinostat (PXD101) in patients with recurrent or refractory peripheral or cutaneous T-cell lymphoma [abstract]. Blood. 2009;114(22):S379.

28. O’Connor OA, Masszi T, Savage KJ, et al. Belinostat, a novel pan-histone deacetylase inhibitor (HDACi), in relapsed or refractory peripheral T-cell lymphoma (R/R PTCL): results from the BELIEF trial. J Clin Oncol. 2013;31(Suppl; absract 8507).

29. Gimsing P. Belinostat: a new broad acting antineoplastic histone deacetylase inhibitor. Expert Opin Investig Drugs. 2009;18(4):501-508.

30. Steele NL, Plumb JA, Vidal L, et al. A phase 1 pharmacokinetic and pharmacodynamic study of the histone deacetylase inhibitor belinostat in patients with advanced solid tumors. Clin Cancer Res. 2008;14(3):804-810.

31. Gimsing P, Hansen M, Knudsen LM, et al. A phase I clinical trial of the histone deacetylase inhibitor belinostat in patients with advanced hematological neoplasia. Eur J Haematol. 2008;81(3):170-176.

32. Steele NL, Plumb JA, Vidal L, et al. Pharmacokinetic and pharmacodynamic properties of an oral formulation of the histone deacetylase inhibitor Belinostat (PXD101). Cancer Chemother Pharmacol. 2011;67(6):1273-1279.
33. Kelly WK, Yap T, Lee J, et al. A Phase I Study of Oral Belinostat (PXD101) in Patients with Advanced Solid Tumors. 2007 ASCO Annual Meeting Proceedings. Vol 25, No 18S (June 20 Supplement), 2007:14092.

34. Zain JM, Foss F, Kelly WK, et al. Final results of a phase I study of oral belinostat (PXD101) in patients with lymphoma. J Clin Oncol. 2009;27:15S(Suppl; absract 8580).

35. Plumb JA, Finn PW, Williams RJ, et al. Pharmacodynamic response and inhibition of growth of human tumor xenografts by the novel histone deacetylase inhibitor PXD101. Mol Cancer Ther. 2003;2(8):721-728.

36. National Comprehensive Cancer Network. Non-Hodgkin's Lymphomas (Version 3.2014). Available at: http://www.nccn.org/professionals/physician_gls/pdf/nhl.pdf. Accessed August 12, 2014.

\section{Publish your work in this journal}

OncoTargets and Therapy is an international, peer-reviewed, open access journal focusing on the pathological basis of all cancers, potential targets for therapy and treatment protocols employed to improve the management of cancer patients. The journal also focuses on the impact of management programs and new therapeutic agents and protocols on

\section{Dovepress}

patient perspectives such as quality of life, adherence and satisfaction. The manuscript management system is completely online and includes a very quick and fair peer-review system, which is all easy to use. Visit http://www.dovepress.com/testimonials.php to read real quotes from published authors. 